\title{
SCHOOL SCIENCE AND MATHEMATICS
}

Vol. X No. 6 Chicago, June, igro Whole No. 80

THE TEACHING OF SEXUAI HYGIENE: MATTER AND METHODS. ${ }^{1}$

\author{
By Winfield S. Hall, PhD., M.D., \\ Professor of Physiology, Northeestern University Medical \\ School, Chicago.
}

The teaching of sexual hygiene must begin in early childhood, and its importance as a part of education should never be lost sight of by parents or teachers until the individual is well launched in the ado'escent period. By the end of puberty, the fifteenth year in girls, and the seventeenth year in boys, the youth should possess sufficient knowledge on sexual matters to protect him not only from the vices that are so likely to become habitual during these years, but also from making mistakes in the case of the sexual system, which might lead to the undermining of the general health.

The development of the sexual equipment and function, and the knowledge of the same, has a double bearing upon development and training of the mind. In the first place, a knowledge of the function of reproduction and a proper attitude of mind regarding it must be recognized by educators to be a necessary part of the equipment of young persons for life. In the second place, parents and teachers are morally bound to treat all questions of sex in the same, simple, straightforward, truthful way that other life problems are treated. In this way only may we expect that a proper mental attitude toward reproduction can be cultivated.

\section{General Considerations.}

Responsibility for the proper instruction of youth in all matters regarding sexual development and the care of the sexual apparatus, together with the great social problem of sexual right living, must in the nature of the case, rest upon the shoulders of the parents.

1This article by Professor Hall gives the method by which he has attained success in teaching sex hygiene by the one-lecture plan. However, he points out that the teaching of the lessons of sex hygiene should begin early and continue through the danger period. He recognizes the ideal character of the biological method in the presentation of facts. - ED. 
However, parents, as a matter of fact, are as a rule not discharging this responsibility. Statistics gathered from a number of representative colleges in the middle states show that only one young man in twenty receives from his parents any adequate instruction on these subjects before leaving home. If such young men, representing such homes, go out into the world uninstructed to grope their way in the darkness of ignorance, what must be the mental condition of the youth from less thrifty families?

This condition of widespread ignorance regarding some of the most fundamentally important questions of social life and individual development came gradually to be understood among educators and professional men and women, and finally a representative body of educators, physicians, clergymen, lawyers, and social workers met in New York City four years ago and organized a Society of Social and Moral Prophylaxis, whose object as indicated in the name of the Society was by the dissemination of information to protect the individual and the body social against the dissemination not only of physical disease, which wrecks both, but of those low ideals and vicious customs which make the highest life impossible.

\section{Segregation.}

The most important lesson learned during several years of $\mathrm{cx}$ perience in presenting this subject to all kinds of audiences is the importance of segregation. By this I mean that boy hearers should be separated from men hearers. Mothers shotld be segregated from fathers. Furthermore, mothers and daughters should be addressed in separate audiences.

The more homogeneous the audience, the more definite and positive may the statements of the speaker be. It is easy to see that in an address to a mixed audience of parents and children, sex problems would have to be discussed in a general and indefinite way. The circumlocutions would be so veiled and the allusions so remote that the speaker would probably be only vaguely understood by the more intelligent and experienced of his audience; while he would probably be grossly misunderstood by the less intelligent and experienced. Let such an audience be segregated along sex lines, namely, the women and girls in one audience, and the men and boys in another. The situation would be somewhat relieved, though not by any means wholly corrected. One can talk more freely to a group of boys when they are alone 
and get more free and frank response from them when he has then alone than he can in the presence of the fathers. The same thing would be true, of course, in an audience of mothers and daughters. Similarly, one would discuss with an audience of fathers certain subjects which boys in the early years of adolescence should not know; such problems as those that concern the ethics of the home, for instance, between husband and wife, problems of maternity and paternity, problems involving the social evils and prostitution. All such matters may be discussed freely and frankly with an audience of men, but, manifestly, youth below the age of seventeen or eighteen should not be present in the audience.

Concerning a division of the audience on age lines, the sexes being mixed, audiences of the parents and then audiences of young people-actual experience makes it clear to me that a public speaker, particularly a physician, can talk more freely to an audience of mothers than to a mixed audience of mothers and fathers. Before stuch an audience of mothers the problems of maternity, paternity, adolescence of the son and danghter, the mother's relation to adolescent youth, even reference to venereal diseases against which the mother should guard her younger children through instruction in the use of public utensils, and against which she should warn her adolescent daughterall these subjects may be discussed freely before an audience of mothers, women teachers and social workers, by a physician. But before a mixed audience of fathers and mothers he instinctively begins to deal in glittering generalities that may mean much or little and that are easily misunderstood.

As to the teaching of the story of life to young people in mixed high school or college classes, there seems to be some difference of opinion among social workers as to how that should proceed. There are in the country a few experienced high school and college teachers of biology, who beginning with the lower animals in their life history and life processes, discuss freely, among other things, reproduction in these lower forms, beginning with the protozoa and passing up step by step to the higher animals until finally reproduction among the mammals is freely discussed as to its biological and physiological relations.

That these teachers ever carry the subject so far as to discuss with their pupils the problem of human sex life, I doubt. However, the student of biology who has followed the subject as far as indicated above, would readily infer a very large part of the application of the general principles to the human subject. 
An attempt to present even the biology of reproduction to a mixed audience of young people in a single address would be in a high degree unwise. As a rule, then, to which there can be few and rare exceptions, the problems of sex should be discussed in homogeneous audiences where one sex and age is segregated from another.

\section{The Matter to be Presented.}

Having divided the hearers into homogeneous groups, what shall be presented to each group? Manifestly, the parents are interested in the far broader field and capable of understanding a far greater range of facts than are the children.

A group of boys of ten to fourteen should be told only those things that boys of that age need to know: for example, questions regarding reproduction: What goes on in an egg during incubation? What has the rooster to do in the process? Where do babies come from? What are general steps of their development within the body of the mother? Why do they begin to develop within the body of the mother? What has the father to do with this process? Then there are questions of physical development in the boy. To many boys these questions do not occur, but they should have them brought to their attention. They should be told how every boy passes through stages in his development in which he assumes gradually the stature, the mental qualities and the functions of manhood. It should be made clear to the boys that, to a large degree, they have it in their hands whether this development shall be a normal one, leading to stalwart virile manhood, or an abnormal one aborted by vicious habits.

A group of older boys, fourteen to seventeen, may be given another chapter in the story of reproduction. Boys of that age are beginning to experience the "Primordial urge" or sexual desire. Many boys of fourteen come to believe that all natural desires should be gratified, but the teacher of sexual hygiene rixust explain to the youths that the fires of passion must be banked, in order that the energies of manhood may be conserved to a time when they may be put to their legitimate use, namely, the begetting of healthy offspring after the establishment of the home.

A matter of the greatest importance for youths of this group tò understand is the influence of internal secretions from the sexual glands upon the body and its development. Most youths have seen the influence of castration upon the development of a young 
male animal. This profound effect is due to the loss of the sexual glands which produce internal secretion, distributed with the blood to muscle and nervous system. Without this secretion the animal never develops those splendid physical and temperamental qualities typical of the male of his species.

The matter to be presented to the girls, young women and mothers, is parallel and analogous to that presented to similar audiences of boys, youths and men.

\section{Method of Presentation.}

How shall this carefully selected matter be presented to the carefully segregated and homogeneous groups? This is a problem of pedagogy. In my presentation of this matter to boys I have used three different methods: the biological, the moral and the "heroic."

The biological method was not a success because I was able to meet the group but once and no adequate biological presentation can be made in one meeting of a class or audience. Several, or better yet, many such meetings should follow in regular succession, where actual living material collected from the plant and animal kingdoms should be presented and studied with the aid of the equipment of a biological laboratory. Manifestly such a presentation is out of the question for social workers, physical directors, and public lecturers. While this must be conceded to be the ideal method of presenting the subject of reproduction and sexual life, it is a method feasible only for the teacher of biolcgy of a high school or college. A physician could, of course, with the facilities of his office, teach a group of boys or of girls, using this biological method, but the physician can rately devote the time required for such a course of study.

The moral method was used after I satisfied myself that the biological method could not be used in the short space of one hour. By the moral method, I refer to an appeal, from a moral standpoint, for right living. After several attempts to stir up boys to a high and noble desire for right living, putting my arguments strictly on a moral basis, I came to the conclusion that the method was not effective, that it did not really stir the boys, and that it would not produce the desired effect.

The heroic method succeeded, because it was based on the human instinct of hero worship. Heroes appeal to boys. When one begins to discuss the real hero, every boy in the audience is awake and alert. He believes in heroes. He hopes to be one. 
He knows a few, and they inspire him to do and to dare. When one gets hold of an audience through discussing with them some great heroes, he has their undivided, almost painful attention when he asks the question: "What is the secret of the hero's success?" "What is the secret of manhood?" and "What can a boy do to grow into the highest type of husky manhood, which alone makes possible heroic deed?" The lecturer can answer these questions in the last five minutes of a forty-five minutes' talk, and leave every boy in his audience convinced and determined.

As to the method of presenting these matters to young people and parents, I an convinced that incomparably the most effective method is a frank presentation of the findings of science. Don't try to point too many morals. If the presentation has been clear and convincing, the listeners will very readily draw their own conclusions and formulate their own morals.

\title{
PHYSIOLOGY AND HYGIENE IN OUR ELEMENTARY SCHOOLS. ${ }^{1}$
}

\author{
By Edgar F. VAN Buskirk, \\ Commercial High School, Brooklyn, N. Y.
}

\section{INTRODUCTION.}

The necessity of teaching physiology and hygiene properly in our elementary schools has been vividly brought home to the writer in a variety of ways. As a college student he discovered that some of his fellow students, although they had mastered difficult subjects, did not know many of the essential facts regarding the care of the body. As a teacher in the elementary schools he became especially interested in teaching physiology and hygiene. Boys, who are old enough to learn the "three R's" and some other common branches, are old enough to be taught that disease germs live in sewage, and that therefore it is not safe to wade in such filth. This specific instance is taken because the author happened to see six or eight barelegged boys ten or twelve years old wading in sewage that was being pumped up into the gutter. A few such sights tend to set one thinking and helped to influence the writer to make a personal investigation of the teaching of physiology and hygiene in our elementary schools.

l'The attention of the reader is called to the interesting distinction made in Mr. Van Buskitk's paper between child interest and adult interest. $\rightarrow$ E. 